\title{
Researching resident responses to New Urban Tourism in Berlin: challenges of interviewee acquisition with a focus on ethnic minorities
}

\author{
Aylin Akyıldız, Marie Duchene and Claudia Ba \\ Technische Universität Berlin IFaculty VIPlanning Building Environment Institute for Architecture IPlanning \\ \& Construction Economics/Real Estate, Germany
}

This research note addresses the difficulties in acquiring interview partners within the Deutsche Forschungsgemeinschaft-funded project 'Neighbourhood in the tourist trap? An examination on the changing residential quality through tourist accommodation in selected Berlin residential neighbourhoods'. The research project is analysing to what extent the quality of residential areas has changed as a result of tourist accommodation through a mixed-method approach. In order to ensure a differentiated database, one aim of the project was to interview residents with different durations of residency and educational levels, and to take into account the high density of people with a migration background in Berlin. Since Berliners of Turkish origin represent the largest group of people with a migration background in Berlin, it was in the interest of the research to make this group's views visible and voices heard. In the research note we focus on the acquisition of Turkish Berliners and reflect on the question of why establishing contacts with Turkish Berliners was especially challenging. In order to answer this question, some hypotheses on non-response conduct will be sketched from which we draw our conclusions of an alteration of acquisition within the field of New Urban Tourism in Berlin.

Keywords: New Urban Tourism, qualitative research, field access, migration background, acquisition, qualitative case study, qualitative methodological techniques, tourism

\section{INTRODUCTION}

Berlin - the city name evokes several pleasant connotations that have been differently used by tourism stakeholders in Berlin. By 2019 more than 13 million visitors were attracted annually (Senatsverwaltung für Wirtschaft, Energie und Betriebe 2020). The number has skyrocketed from about three million since 1996 (ibid.). Berlin's image was shaped by myths of opportunity and open space, 'an underdog lovability while being rough and dirty and down on its luck' (Brandt et al. 2019: 379). The image of the city as a centre for the arts and alternative lifestyles has been consistent and plays a part in the city's appeal to a new form of tourism.

In the context of an increasing interest in city tourism (Judd/Fainstein 1999; Hoffman et al. 2003), a new type of tourism called New Urban Tourism has become of interest in tourism research (Maitland/Newman 2004; Selby 2004; Novy 2010; Füller/Michel 2014; Dirksmeier/Helbrecht 2015). New Urban Tourists are less interested in 'classical' sights, but are instead in search of local flair, looking to immerse 
themselves in the everyday life of the visited city and the 'authentic' local attitude towards life in general (Novy 2010). This form of tourism is accompanied by new possibilities of travel planning, namely peer-to-peer renting platforms such as Airbnb, and has brought about intense discussions about misuse of rental in an increasingly difficult housing market in Berlin (Novy 2013; Kritische Geographie Berlin 2014; Holm 2016).

Berlin has a traditional tenant market with a rent share of approximately 85 per cent (Voigtländer/Seipelt 2016) with a lower ownership rate than the national average (national average, 2018: 46.5 per cent, Berlin, 2018: 17.4 per cent; Statista Research Department 2020a). Between 2005 and 2018 the median rent increased from €5/sqm to $€ 9.90 / \mathrm{sqm}$, with peaks of over $€ 15 / \mathrm{sqm}$ in popular inner-city neighbourhoods (Statista Research Department 2020b) while the vacancy rate dropped from 5.7 per cent in 2006 to 0.8 percent in 2019 (ibid.). In well-demanded inner-city areas, privately or commercially sub-let holiday apartments account for up to 3 per cent of the total rentable living space (GEWOS 2012). Especially one- and two-room apartments, which are highly demanded by inhabitants and tourists alike, can be assumed to be the subject of increased tension (Skowronnek et al. 2015; Braun/ Schäfer 2016). Therefore, the discussion about rental prices is of particular importance to Berlin's specific housing market.

Nevertheless, the effects of holiday homes and tourism on residents have been little researched to date: in recent years, social sciences have dealt with the concept of Quality of Life (hereinafter QoL). Understood as a subjective assessment of social, economic, emotional and health wellbeing, the concept of QoL is also interesting for parts of tourism research that deal with the attitudes of residents with regard to tourism development (Andereck/Nyaupane 2011; Uysal et al. 2012). In spite of this, tourism as an influencing factor is rarely included in analysis when considering the QoL in terms of 'residential quality'. Only a few explicitly include tourism as an influencing factor (Biagi et al. 2006). The Deutsche Forschungsgemeinschaft (DFG)-funded 'Neighbourhood in the tourist trap? An examination on the changing residential quality through tourist accommodation in selected Berlin residential neighbourhoods' ${ }^{1}$ aims to contribute to the debate by closing this research gap.

In this research note we reflect on the challenges that arose during field access and research, notably the acquisition of residents for semi-structured interviews on their perception of the changes in residential quality brought about by tourism.

\section{RESEARCH DESIGN}

Through a mixed-method approach, the research seeks to bring together qualitative and quantitative methods from both real-estate economic studies and sociology,

1. The research presented in this paper was conducted as part of an ongoing research project named 'Neighbourhood in the tourist trap? An examination on the changing residential quality through tourist accommodation in selected Berlin residential neighbourhoods', which is conducted in inter-disciplinary collaboration between the chair for Urban Sociology and Sociology of Space at Technische Universität Darmstadt (Sybille Frank) and the chair for Planning and Construction Economics/Real Estate (Kristin Wellner). The project is funded by the German Research Foundation - DFG (Sachbeihilfe: GZ: FR 2522/5-1 \& WE 5894/2-1). 
utilizing cartography, market analysis, media analysis, focus groups and semistructured interviews with inhabitants. Nevertheless, we want to concentrate on the acquisition of interviews in the following. As Berlin's population is historically strongly composed of migrants, mainly of Turkish origin, it was of particular interest to make these groups' views visible and voices heard. We will dedicate a larger section of this research note to the question of why establishing contacts with Turkish Berliners was especially difficult and reflect on the ethnographical difficulties experienced during acquisition. ${ }^{2}$ This will allow us to sketch some hypotheses on nonresponse from the conduct of potential interviewees.

\subsection{Different quarters - different tourism - different perceptions}

The case selection is based on two categories: first on the residential areas studied and second on the sample of residents interviewed. The survey areas are defined on the basis of the so-called livelihood-oriented spaces (Lebensweltlich orientierte Räume, LOR). ${ }^{3}$ Four LORs were selected according to the density of formal (hotels and hostels) and informal short-term rentals (Airbnb). Taking a comparative perspective, the study is conducted in one LOR with a high number of formal and one with a high number of informal tourist accommodation. In addition, and for control purposes of the data, a neighbourhood strongly influenced by both types of tourism and a neighbourhood which is only slightly affected by tourism were included in the study. This selection follows the assumption that a neighbouring hotel or hostel has different effects on subjectively felt residential quality than the presence of tourists in neighbouring dwellings or within the own housing unit.

\subsection{Selection of interviewees}

Interviewees are selected through a criteria-led quota sample (Behnke et al. 2006). Assuming that demands for residential quality are likely to vary with regard to gender and the level of education, a selection is made accordingly (educational level: low, medium, high; gender: female, male) (Hoffmeyer-Zlotnik/Warner 2014). In addition, the period of residency is included as a criterion in the quota plan (two to under six years; six years and longer) as we assume that those who have lived in a neighbourhood for long might respond to changes in neighbourhood life differently than those who moved to the neighbourhood only recently. This results in 12 attribute combinations. One interview is to be conducted per attribute combination and case study area (12 per residential area, corresponding to a total of 48 interviews). Since Berlin has a migrant share of 35 per cent (Amt für Statistik Berlin-Brandenburg 2020) and the largest group is of Turkish origin, three tenants with a Turkish migration background

2. To reflect on the subjectivity of the researchers involved in this process, Franz Breuer's methodological article on ethnographic fieldwork unfolds the researcher's persona in regard to standpoint, language advantages and the construction of knowledge during acquisition (Breuer 2003).

3. German: LOR = Lebensweltlich orientierter Raum. A spatial basis with a homogeneity of living environment, established in 2006 by the Senate resolution for planning, forecasting and monitoring demographic and social developments in Berlin (Senatsverwaltung für Stadtentwicklung und Wohnen 2019). For more elaborate reflections within the research project on the selected LORs we recommend the paper by Brandt et al. (2019). 
were to be interviewed in each LOR, not following the aforementioned criteria. We conducted these interviews in German or Turkish.

According to the German Federal Office for Migration and Refugees (BAMF), a person has a migration background if they themselves or at least one of their parents were born abroad and migrated to Germany. This definition includes immigrated and non-immigrated foreigners, immigrated and non-immigrated naturalized citizens, German immigrants and the descendants of the aforementioned three groups with a German citizenship (Bundesamt für Migration und Flüchtlinge, n.d.). According to this categorization, children of immigrants are subject to othering, even though they were born and raised in Germany. For this reason, the use of the term migration background outside of statistical considerations is disputed. We have decided to use the term migration background in this research for persons who either immigrated from Turkey themselves or who have at least one parent who has immigrated. Although taking this prefixed term of 'Turkish' Berliners into account, we didn't assume at any stage that we would be dealing with a homogenous community (Brunt 2001).

\subsection{Field access and non-response in tourism-related research}

Approaching the field as one of the first steps in research is often given little attention. Many researchers view field access as something that has to be done in order for the 'actual' research to start (Wolff 2000). However, field access requires a lot of work, patience and perseverance, and can take weeks or even months before initial contacts are established (Taylor et al. 2016). Through this period of gaining access, researchers often experience frustration, self-doubt and failure (ibid.).

Failure in field access is based, among other things, on non-response, which means dealing with the lack of data in the pre-selected sample unit (Schnell 1997). Since it is never quite possible to attain all interviews within all pre-selected target groups, an inequality arises in the sample. This is ascribable to the difference between the originally targeted number of units and the real sample size. The resulting distortion evokes non-responses as a possible source of error (Koch/Blohm 2015).

As Wolff argues, the difficulties in acquisition do not appear in later documentation of the research project, yet they represent, in fact, critical moments in the analysis of the field (Wolff 2000). For this reason, we argue that field access is an integral part of qualitative research in cultural and social sciences. Failures as well as the reactions to them are part of the way the research is conducted, and their reflection provides a great deal of information about the nature of the research itself and the composition of the field (Breidenstein et al. 2013).

Furthermore, the course and evolution of field access determine the representation of the field reality (Pickel/Sammelt 2014). Consequently, researchers should reflect on the sample and repeatedly consider the researched fields and represented reality of the sample (ibid.). Accordingly, field access is not an entry obstacle that needs to be overcome before the real data is gathered, but a recurring process of reflection that accompanies the researchers throughout the entire research project and should therefore be made accessible in research documentation (Wolff 2000). 


\section{CASE STUDY}

Different recruitment strategies were applied over a period of eight months for the acquisition of interview partners (April to November 2019). We utilized a snowball system via personal contacts and gatekeepers in associations, neighbourhood centres and educational institutions. In addition, flyers and posters in German and Turkish were distributed at various times in all LORs and mailings were sent to several institutions. Postings in social media, placements of newspaper advertisements and the attendance of local events such as a neighbourhood get-together or the Friday prayer at mosques were additional strategies to access potential interviewees.

Despite all initial intensive efforts, there was little reaction from the tenants both with German and migratory background. Even a compensation of $€ 20$ per interview did not yield enough interest to meet the initially planned sample size. The recruitment of residents with a Turkish migratory background proved to be particularly challenging. In the following, we will reflect on the strategies used and the reactions obtained by potential interviewees.

\subsection{Institutions}

We concentrated our recruiting efforts initially on institutions that have a special connection to the Turkish migrant community, such as German-Turkish associations and educational institutions. Contrary to our expectations of finding access, we received rather negative reactions, most notably from one organization working with and for migrants. The organization referred to pejorative media coverage of migrants in Germany and refused further cooperation on the grounds that they wanted to protect their clients and participants from negative portrayal, even in academic research. After several redundant approaches and the repeated assurance of anonymity of the persons involved, communication opened up again, but there was still no space for cooperation.

Other institutional contacts were more open to cooperating and facilitating contact with Turkish Berliners. One interviewee was reached via a district museum that has no specific Turkish focus. The concerns of the research project coincided with the interviewee's personal interests, who is politically active in the neighbourhood and therefore interested in voicing their opinion. The migration background of the person probably played a secondary role in their decision to participate.

\subsection{Personal contacts}

Recruitment through personal contacts proved to be simpler and more of a success. One interview partner was mediated due to acquaintances of one of the colleagues within the project; another contact resulted from a referral from a previously interviewed Turkish Berliner. The newly addressed interview partner stressed that they might not have participated in the project, if they had not already received information about the interview from a reliable personal contact.

These experiences exemplify that access to a community as an 'outsider' is difficult and that the research field can most easily be facilitated by existing personal connections. The various networks that make up a certain research field are partially invisible and inaccessible to researchers beforehand and cannot be included in a calculation. These personal networks are often informal and the result of relationships and daily interactions. They may only become visible to the researcher by long-term 
and narrow engagement in the field. In hindsight personal networks can create the necessary basis of trust. From this arise risks of selection biases and the importance of the abovementioned reflection of representation becomes crucially relevant.

\subsection{Social media}

The use of social media created larger visibility for the project. Lots of reactions were gained through postings on Facebook. Nevertheless, only three Turkish Berliners showed serious interest, of which only one person was eligible for an interview. Since Facebook is used to maintain contacts, advertising for an academic study may eventually not have been noticed in this context. In addition, due to permanent content creation and information flow on Facebook, our posts in the group pages soon became outdated by others. That could be another reason why this recruiting strategy didn't prove itself as successful as we had hoped for.

\subsection{Interest and accessibility}

The findings on social media lead to a further observation that was made during acquisition. People interested in the research project often had a similar profile, which meant that many had to be rejected in order to avoid sample duplications. In all research areas, this was particularly the case for people with a higher level of education or tenants of the middle class.

Language, appearance and other characteristics which constitute a person's habitus attract attention especially from people within the same social milieu. Even though the observations made throughout our research have confirmed this structural problem of academic studies, the question remains as to why we have not managed to address Turkish Berliners with a similar social background to ours. This leads to questions of identity: Do those who were born and raised and who studied in Germany and, therefore, are part of the academic setting, feel addressed by the Turkish posters? Would they want to identify themselves as being Turkish or of Turkish origin in an interview? At this point the difficulty of defining people on the basis of their migration background becomes apparent once again.

Furthermore, some people refused to participate in academic research, claiming that it wouldn't bring any change about. Residents of the neighbourhoods may therefore have felt addressed by the content of the research project but may have been discouraged from participating due to the lack of a direct social and political benefit.

\subsection{Direct contacts and events}

When recruiting interview partners with a migration background, a direct approach and personal contact were often used, for example at farmers' markets and in neighbourhood shops. However, this proved to be unsuccessful. Many shop owners and visitors assumed that the interview was to be conducted on the spot, which was declined immediately because it was an inconvenience for the people addressed. Visits to local mosques after the Friday prayer were also unsuccessful. The congregation attending the Friday prayer used the opportunity to strengthen contacts within their community and did not pay much attention to the project employee. Moreover, as Fridays are holy in Islam, some Muslims may have considered the acquisition for a research project as inappropriate and irrelevant in this context. Since the mosques were largely attended by men only, some of the attendees may have been further 
irritated or even disturbed by the presence of a female project employee within the facility, even if the efforts were encouraged by the Imam.

\subsection{Identity: self and external images}

Direct contact as an opportunity to access the field implicated far-reaching difficulties about the representation of the self and the other within society, for example assumptions about origin because of engagement in institutions or religious practices linked to groups with a migration background were less applicable than presumed. When we approached Turkish-born Berliners, we explicitly searched for 'Turkish' facilities and shops. Some institutions referred to Turkey in their names, but we also drew our conclusions on 'Turkishness' through external characteristics such as language and approached the owners of 'Turkish' bakeries and late-night kiosks (Spätis). In one attempt to contact a store owner, who listened to Turkish music while he was talking to a colleague in Turkish, he negated the question of whether he had a Turkish background and rejected any further conversation. Another rejection was experienced during a conversation with a group of Turkish people. Despite repeated declarations that they were eligible for the research project, they did not feel that they belonged to the target group.

The question of origin and belonging, self-description and external attribution seems to have been the wrong approach in many cases. As outlined at the beginning of the research note, the aim was to integrate people with a migration background, who represent a large part of the Berlin population. Through the distribution of posters in Turkish as well as the external cultural attribution, which often differ from the self-image, a form of othering was unconsciously practised and performed, which resulted in the described rejections.

The migration background as a political field with negative connotations brings the difficulty of no neutral questioning on the topic. Hence, it turned out to be an even more difficult process for the project employees to include people with a migration background in the study without putting third-party attributions at the centre of the acquisition.

Due to the limited feedback from people with a migration background, we decided to open up the definition of migration background within the project's sample plan. From then on, interviewees did not have to have experienced migration themselves; partial parental migration sufficed. Changing the selection scheme once more raised the question of who 'counts' as Turkish and how respondents perceive themselves. We had to reflect on our contribution to exclusionary research and re-evocation of patterns of othering and attribution in the effort to make the voices of Turkish Berliners heard.

\section{CONCLUSION: FIELD ACCESS IN TOURISM-RELATED RESEARCH}

Scientific knowledge, especially in the context of qualitative research in social sciences, is inherently subjective (Breuer/Roth 2003). This is due, among other things, to the position and the perspective that the researcher adopts, consciously or unconsciously, within the research field (ibid.). However, instead of considering the subjective nature of scientific research as a deficiency or a default, the (self-)reflexion of 'the embodied researcher, who bears social, historical, socialized, and biographical characteristics' (ibid.: para 13) opens up new ways of producing knowledge. Acknowledging the researcher's cultural background and social position with regard to the 
subjects of interest is a first important step. The project employee who contacted Berliners with a migration background is of Turkish origin herself. This means that being defined as a Berliner with a migration background was common ground for both the researcher and the target group and, apart from that, thanks to the project employee's skills, eventual language barriers could be prevented.

Despite these characteristics of representation, the researcher wasn't able to position herself within the community and dealt with the rejection and the subjective feeling of being an 'outsider'. This was, on the one hand, due to the fact that the employee herself - like probably many interviewees - only partially identifies with the target group or sees herself as a Berliner with a migration background. On the other hand, the employee only recently moved to Berlin and was therefore unable to rely on a pre-existing network. These two conditions, intertwined, did not result in creating various contacts; rather, the language offered the access.

The first attempts to contact possible interview partners with a migration background were made in German. Due to the lack of positive replies, further approaches were made in Turkish. The adaption of the language proved to be a better strategy the previous experiences of rejection were overcome and a connection was established, although it did not result in interviews for the most part. Thus, it was not the 'Turkishness' or having a Turkish migration background that became the foundation of the acquisition, but rather it was the linguistic access.

These approaches show that a culture-sensitive method to the field is necessary. This should be accompanied by a differentiated focus on the circumstances under which people ought to be approached. Considering the former, the following questions could be asked before and during the performing of the acquisition processes in the future:

- What language is suitable for a culture-sensitive acquisition?

- Where and when are potential interview partners contacted in the best way?

- Which institutions or events are best suited in order to respect culture-specific practices?

- To what extent does the researcher's profile have an adverse or a positive effect on the recruitment process?

- What is the researcher's role when entering the field and how does this change in the research process (Breuer/Roth 2003)?

It is of great importance that possible discriminatory ways of thinking and approaches are avoided. Othering should not be (re)produced, which is precisely what we wanted to address through a balanced approach to research. For this purpose, it is important to consider why it makes sense to survey other ethnic population groups and their values and interests in this research.

Our experiences show that it takes a lot of time and intensive work to create a basis of trust in order to expect a successful cooperation.

Changing our definition of people with a migration background within the research project shows an inherent problem with defining communities through migration history; these definitions are arbitrary. The question of who belongs to a community and who does not is far more complex than personal or family migration history, and even constructing concepts of first or second migrant generations reproduces an otherness that may counteract the sense of inclusion that was the intent of our research. The task of forming reasonably executable categorizations in order to attain comparable data seems to be especially difficult for marginalized communities, as membership in these comes with a certain political and cultural history that may lead 
to adverse reactions to a generalized categorization. One must question whether it is not more sensible to examine the field of research from a non-ethnic point of view.

Nevertheless, many residents of the research areas were reached by applying the recruitment strategies mentioned above, which in the end brought about a diverse sample of interviewees who provided valid results rich in perspectives to the research project. Through failed recruitments, the project gained valuable insights into the structures and networks of the research areas, which will be of great benefit in the further procedure and in the analysis of the results.

\section{REFERENCES}

Amt für Statistik Berlin-Brandenburg (ed.) (2020): Statistischer Bericht: Einwohnerinnen und Einwohner im Land Berlin am 31 Dezember 2019, URL: https://www.statistik-berlinbrandenburg.de/publikationen/stat_berichte/2020/SB_A01-05-00_2019h02_BE.pdf (accessed 23 June 2020).

Andereck, K.L., Nyaupane, G.P. (2011): Exploring the nature of tourism and quality of life perceptions among residents, in: Journal of Travel Research, 50(3), 248-260.

Behnke, J., Baur, N., Behnke, N. (2006): Empirische Methoden der Politikwissenschaft, Stuttgart: UTB.

Biagi, B., Lambiri, D., Royuela, V. (2006): Quality of life in the economic and urban economic literature, CRENoS Working Paper, University of Cagliari and Sassari.

Brandt, S., Müller, C., Raschke, A.L. (2019): Nuisance or economic saluation: the role of new urban tourism in today's Berlin, in: Čamprag, N., Suri, A. (eds), Conference Proceedings: Three Decades of Post-Socialist Transition, Darmstadt: Universitäts- und Landesbibliothek Darmstadt, 378-383.

Braun, N., Schäfer, P. (2016): Misuse through short-term rentals on the Berlin housing market, in: International Journal of Housing Markets and Analysis, 9(2), 287-311.

Breidenstein, G., Hirschauer, S., Kalthoff, H., Nieswand, B. (2013): Ethnografie: Die Praxis der Feldforschung, Konstanz and München: UVK.

Breuer, F. (2003): Subjekthaftigkeit der sozial-/wissenschaftlichen Erkenntnistätigkeit und ihre Reflexion: Epistemologische Fenster, methodische Umsetzungen, in: Forum Qualitative Sozialforschung, 4(2), Article 25, URL: https://www.qualitative-research.net/index.php/fqs/ article/view/698/1508 (accessed 19 August 2020).

Breuer, F., Roth, W.M. (2003): Subjectivity and reflexivity in the social sciences: epistemic windows and methodical consequences, in: Forum: Qualitative Social Research, 4(2), Article 25, URL https://www.qualitative-research.net/index.php/fqs/article/view/698/1511 (accessed 19 August 2020).

Brunt, L. (2001): Into the community, in: Atkinson, P., Coffey, A., Delamond, S., Lofland, J., Lofland, L. (eds), Handbook of Ethnography, London: SAGE Publications, 80-91.

Bundesamt für Migration und Flüchtlinge (n.d.): Glossar: Migrationshintergrund, URL: https:// www.bamf.de/DE/Service/ServiceCenter/Glossar/_functions/glossar.html;jsessionid=0B9F DD8292C90E0430FE6B0C09F86E3E.internet532?nn=282918\&cms_lv2=282966 (accessed 9 June 2020).

Dirksmeier, P., Helbrecht, I. (2015): Resident perceptions of New Urban Tourism: a neglected geography of prejudice, in: Geography Compass, 9(5), 276-285.

Füller, H., Michel, B. (2014): 'Stop being a tourist!' New dynamics of urban tourism in Berlin-Kreuzberg, in: International Journal of Urban and Regional Research, 38(4), 13041318.

GEWOS (2012): Indikatorensystem zur kleinräumigen Wohnungsmarktanalyse, Report, GEWOS Institut für Stadt-, Regional- und Wohnforschung.

Hoffman, L.M., Fainstein, S.S., Judd., D.R. (2003): Cities and Visitors: Regulating People, Markets, and City Space, Malden: Blackwell. 
Hoffmeyer-Zlotnik, J.H.P., Warner, U. (2014): Sozialdemographische Standards, in: Baur, N., Blasius, J. (eds), Handbuch Methoden der empirischen Sozialforschung, Wiesbaden: Springer, 733-745.

Holm, A. (2016): Wie verändert Airbnb den Wohnungsmarkt? Eine Politische Ökonomie der Ferienwohnungen am Beispiel Berlin: analyse \& kritik, zeitung für linke Debatte und Praxis (617), 21 June, URL: http://www.akweb.de/ak_s/ak617/47.htm (accessed 30 June 2020).

Judd, D.R., Fainstein, S.S. (1999): The Tourist City, New Haven, CT: Yale University Press.

Koch, A., Blohm, M. (2015): Nonresponse bias, Survey Guideline, Mannheim: GESIS Leibniz-Institut für Sozialwissenschaften (GESIS Survey Guidelines).

Kritische Geographie Berlin (2014): Touristification in Berlin, in: Sub \urban, 2(1), 167-180.

Maitland, R., Newman, P. (2004): Developing metropolitan tourism on the fringe of central London, in: International Journal of Tourism Research, 6, 339-348.

Novy, J. (2010): What's new about new urban tourism? And what do recent changes in travel imply for the 'tourist city' Berlin?, in: Richter, J. (ed.), The Tourist City Berlin: Tourism and Architecture, Salenstein: Braun, 190-199.

Novy, J. (2013): 'Berlin does not love you': notes on Berlin's 'tourism controversy' and its discontents, in: Bernt, M., Grell, B., Holm, A. (eds), The Berlin Reader: A Compendium on Urban Change and Activism, Bielefeld: Transcript (Urban studies), 223-237.

Pickel, G., Sammelt, K. (2014): Einführung in die Methoden der sozialwissenschaftlichen Religionsforschung, Wiesbaden: Springer.

Schnell, R. (1997): Nonresponse in Bevölkerungsumfragen: Ausmaß, Entwicklung und Ursachen, Opladen: Leske \& Budrich.

Selby, M. (2004): Understanding Urban Tourism: Image, Culture and Experience, London: I.B. Tauris.

Senatsverwaltung für Stadtentwicklung und Wohnen (2019): Lebensweltlich orientierte Räume (LOR) in Berlin, URL: https://www.stadtentwicklung.berlin.de/planen/basisdaten _ stadtentwicklung/lor/ (accessed 29 June 2020).

Senatsverwaltung für Wirtschaft, Energie und Betriebe (2020): Tourismus in Zahlen, URL: https://www.berlin.de/sen/wirtschaft/wirtschaft/branchen/tourismus/tourismus-in-zahlen/ (accessed 23 June 2020).

Skowronnek, A., Vogel, L., Parnow, J. (2015): Airbnb vs. Berlin. Was sagen die Daten?, URL: www.airbnbvsberlin.de (accessed 29 June 2020).

Statista Research Department (ed.) (2020a): Eigentümerquote in Deutschland im Zeitraum von 1998 bis 2018 nach Bundesländern, URL: https://de.statista.com/statistik/daten/studie/ 155713/umfrage/anteil-der-buerger-mit-wohneigentum-nach-bundesland/ (accessed 23 June 2020).

Statista Research Department (ed.) (2020b): Entwicklung der Angebotsmieten für Berlin von 2004 bis zum 1. Quartal 2019, URL: https://de.statista.com/statistik/daten/studie/535119/ umfrage/mietpreise-auf-dem-wohnungsmarkt-in-berlin/ (accessed 29 April 2020).

Taylor, S.J., Bogdan, R., DeVault, M.L. (2016): Qualitative Research Methods: A Guidebook and Resource, 4th edn, Hoboken, NJ: John Wiley.

Uysal, M., Perdue, R.R., Sirgy, M.J. (eds) (2012): Handbook of Tourism and Quality-of-Life Research: Enhancing the Lives of Tourists and Residents of Host Communities, Dordrecht: Springer.

Voigtländer, M., Seipelt, B. (2016): Implikationen der Niedrigzinsphase für die Wohneigentumsbildung, Report, Köln: IWGutachten.

Wolff, S. (2000): Wege ins Feld und ihre Varianten, in: Flick, U., Von Kardoff, E., Steinke, I. (eds), Qualitative Forschung: Ein Handbuch, Reinbek bei Hamburg: Rowohlt, 334-349. 